\title{
PEGylated self-assembled enzyme-responsive nanoparticles for effective targeted therapy against lung tumors
}

\author{
Fangyuan Guo, Jiangqing Wu, Wenchao Wu, Dongxue Huang, Qinying Yan, Qingliang Yang, Ying Gao \\ and Gensheng Yang*
}

\begin{abstract}
Background: Matrix-metalloproteinases, which are overexpressed in many types of cancer, can be applied to improve the bioavailability of chemotherapeutic drugs and guide therapeutic targeting. Thus, we aimed to develop enzyme-responsive nanoparticles based on a functionalized copolymer (mPEG-Peptide-PCL), which was sensitive to matrix metalloproteinase, as smart drug vesicles for enhanced biological specificity and reduced side effects.

Results: The rate of in vitro curcumin (Cur) release from Cur-P-NPs was not markedly accelerated in weakly acidic tumor microenvironment, indicating a stable intracellular concentration and a consistent therapeutic effect. Meanwhile, P-NPs and Cur-P-NPs displayed prominent biocompatibility, biostability, and inhibition efficiency in tumor cells. In addition, Cur-P-NPs showed higher fluorescence intensity than Cur-NPs in tumor cells, implying enhanced cell permeability and targeting ability. Moreover, the internalization and intracellular transport of Cur-P-NPs were mainly via macropinocytosis. Studies of pharmacodynamics and cellular uptake in vitro and biodistribution in vivo demonstrated that Cur-P-NPs had stronger target efficiency and therapeutic effect than Cur-DMSO and Cur-NPs in tumor tissue.
\end{abstract}

Conclusion: Results indicate that Cur-P-NPs can be employed for active targeted drug delivery in cancer treatment and other biomedical applications.

Keywords: Enzyme-responsive nanoparticles, Cell-penetrating peptide, Matrix metalloproteinase, Cellular uptake, Tumor extracellular environment

\section{Background}

Lung cancer is currently one of the most prevalent cancers in the world with high morbidity and mortality [13]. In developing countries, in particular, the increasing incidence of lung cancer has not been effectively controlled [4, 5]. Histologically, lung cancer is classified as small-cell lung cancer (SCLC) and non-small cell lung cancer (NSCLC). Due to the high prevalence of tobacco consumption, NSCLC is found to occur more commonly compared to SCLC [6, 7]. Several researchers have reported that neoangiogenesis is a significantly negative prognostic factor in lung cancer $[8,9]$. Therefore, an

*Correspondence: yanggs@zjut.edu.cn

College of Pharmaceutical Science, Zhejiang University of Technology, \#18 Chaowang Road, Hangzhou 310032, People's Republic of China effective anti-angiogenesis drug for NSCLC therapy is urgently required. Curcumin (Cur), an active substance extracted from turmeric, has been widely studied for its anti-inflammatory [10], anti-angiogenic [11], antioxidant [12], wound healing [13, 14], and anti-cancer effects [15]. Furthermore, Cur can reverse chemo-resistance by inhibiting multiple signaling pathways. However, its poor water solubility, structural instability, low membrane permeability, and bioavailability has greatly inhibited the application of Cur in clinic.

In the last two decades, nanotechnology has been greatly developed in the arena of biomedicine, pharmaceuticals, and drug delivery $[16,17]$. Nanoparticles, one of the representative nano delivery systems, are developed for use in oncotherapy due to specific properties, such as surface modification, good stability, and low toxicity [18]. 
However, indistinctive tumor cell specific uptake and the rapid elimination of nanoparticles by the reticuloendothelial system (RES) are still barriers in efficient drug delivery in vivo [19]. To address these challenges, functionalized nanoparticles such as magnetic nanoparticles [20-22], redox-sensitive nanoparticles [23], pH-response nanoparticles [24, 25], and enzyme-response nanoparticles [26-28] were designed. Because specific enzymes are overexpressed in tumor cells, enzyme-responsive nanoparticles can be an excellent candidate for designing a smart drug delivery system. Matrix metalloproteinases (MMPs) are over-expressed in many types of cancer. Therefore, they are logical targets for enzyme-triggered therapeutics. MMP targeting peptides have been successfully designed $[29,30]$. In addition, increasing evidence demonstrates that cell penetrating peptides (CPPs) can help to enhance the ability of cell penetration in cargo delivery. Therefore, the combination of targeting peptides and CPPs could be a potential strategy for improving the effectiveness of cancer therapy.

In this study, we successfully synthesized a novel enzyme-responsive nanoparticle based on a tri-block biomaterial (mPEG-Peptide-PCL), which reconfigures in response to MMPs that are active and overexpressed in cancers, to guide therapeutic targeting. In mPEGPeptide-PCL, PCL was used for drug loading; (ACP)GPLGIAGQr9-(ACP) was selected as the targeting peptide. GPLGIAGQ was designed for degradation by MMP-2 [31], and the exposed cell penetrating peptide r9 would enhance the cellular uptake of nanoparticles [32]; PEGylation could improve the stability of the carrier, and prolong the retention time in vivo. Thereafter, the nanoparticle was prepared by the solvent evaporation method. In vitro, the accumulative releasing rate of the drug (Cur as the model drug) in different $\mathrm{pH}$ conditions was also evaluated. Furthermore, the toxicity and cellular uptake (including mechanism study) of the biomaterials were assessed in L929 mouse embryonic fibroblasts and NSCLC A549 cells. In vivo, due to a strong fluorescence effect of Cur, the selective targeting behavior and biodistribution of mPEG-Peptide-PCL nanoparticles were measured using an in vivo imaging system.

\section{Methods}

\section{Materials}

Cur was purchased from Hangzhou Guang Lin Biological Pharmaceutical Co. Ltd. (Hangzhou, China). (ACP)GPLGIAGQr9-(ACP) was from ChinaPeptides Co. Ltd. (Shanghai, China). Poloxamer188 was obtained from BASF (Shanghai, China). Stannous 2-ethylhexanoate $\left[\mathrm{Sn}(\mathrm{Oct})_{2}\right]$ was obtained from Sigma (St. Louis, MO, USA). Dialysis bags $(\mathrm{MWCO}=14,000)$ were obtained from Gene Star Co. (Shanghai, China). L929 mouse embryonic fibroblasts and A549 cells were from the Cell Bank of the Chinese Academy of Sciences (Beijing, China). Kunming mice were obtained from Zhejiang Academy of Medical Sciences (Hangzhou, China). mPEG $(\mathrm{Mn}=1900)$ and $\varepsilon$-caprolactone $(\varepsilon-\mathrm{CL})$ were purchased from Aladdin Chemicals (Shanghai, China). Other reagents (analytical or chromatographic grade) were obtained from Aladdin Chemicals.

\section{Synthesis of tri-block copolymer}

mPEG-Peptide-PCL was prepared using the segmented synthetic way with mPEG-NHS, peptide and PCL-NH as different sections. The detailed process has been shown in Fig. 1.

\section{Synthesis of PCL-NH}

2-(tert-Butoxycarbonylamino)-1-ethanol (922.1 $\mathrm{mg}$, $5.72 \mathrm{mmol}), \varepsilon$-caprolactone $(9.9987 \mathrm{~g}, 87.6 \mathrm{mmol})$, and $\mathrm{Sn}(\text { Oct })_{2}$ (catalyst, $40 \mu \mathrm{L}, 0.124 \mathrm{mmol}$ ) were mixed in a $100 \mathrm{~mL}$ three-necked flask. Then a polymerization reaction was performed at $120^{\circ} \mathrm{C}$ under dry nitrogen for $24 \mathrm{~h}$. PCL-NHtBoc was purified by precipitation in cold methanol to remove the unreacted monomer and oligomer, and the purified product was obtained after filtration and vacuum drying at $40^{\circ} \mathrm{C}$ for $24 \mathrm{~h}$.

PCL-NHtBoc $(5 \mathrm{~g})$ was dissolved into DCM $(20 \mathrm{~mL})$, and $4 \mathrm{~mL}$ trifluoroacetic acid was added to the solution; the solution was stirred for $8 \mathrm{~h}$ at $0{ }^{\circ} \mathrm{C}$ under dry nitrogen. After the reaction was completed, the crude copolymer $\left(\mathrm{PCL}-\mathrm{NH}_{2}\right)$ solution was washed with saturated $\mathrm{NaHCO}_{3}$ solution and distilled water; the extraction process was repeated three times. DCM solution was collected and added drop-wise to cold methanol (1:15, v/v). PCL-NH was purified by precipitation, and obtained after filtration and vacuum drying at $40{ }^{\circ} \mathrm{C}$ for $24 \mathrm{~h}$. The number average molecular weight $(\mathrm{Mn})$, the weight-average molecular weight $(\mathrm{Mw})$, and polydispersity index (PDI) of PCL$\mathrm{NH}_{2}$ were measured by Gel Permeation Chromatography (GPC) analysis [33].

\section{Synthesis of mPEG-NHS}

mPEG (Mw: 1900, $7.6 \mathrm{~g}, 4 \mathrm{mmol})$ and butanedioic anhydride $(0.8 \mathrm{~g}, 8 \mathrm{mmol})$ were dissolved in pyridine $(60 \mathrm{~mL})$, then 4-dimethylaminopyridine (DMAP, $73.3 \mathrm{mg}$, $0.6 \mathrm{mmol}$ ) and triethylamine $(404.8 \mathrm{mg}, 4 \mathrm{mmol})$ were added, followed by mixing of the solutions. The mixture was stirred under dry nitrogen at room temperature for $24 \mathrm{~h}$. After the reaction was completed, the crude product was dissolved in DCM $(20 \mathrm{~mL})$ and precipitated into cold ethyl ether $(1: 15, \mathrm{v} / \mathrm{v})$. The precipitate (mPEG$\mathrm{COOH}$ ) was dried in vacuo at $25{ }^{\circ} \mathrm{C}$ for $48 \mathrm{~h}$ to remove the solvent. 
(1)

$\mathrm{n}$

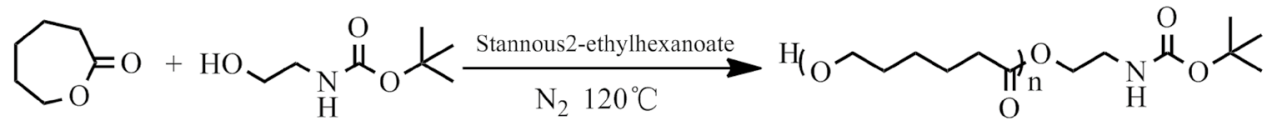

PCL-NHtBoc<smiles>CC(C)(C)OC(=O)NCCOC(=O)CCCCCO</smiles>

PCL-NHtBoc

PCL-NH 2

(2)
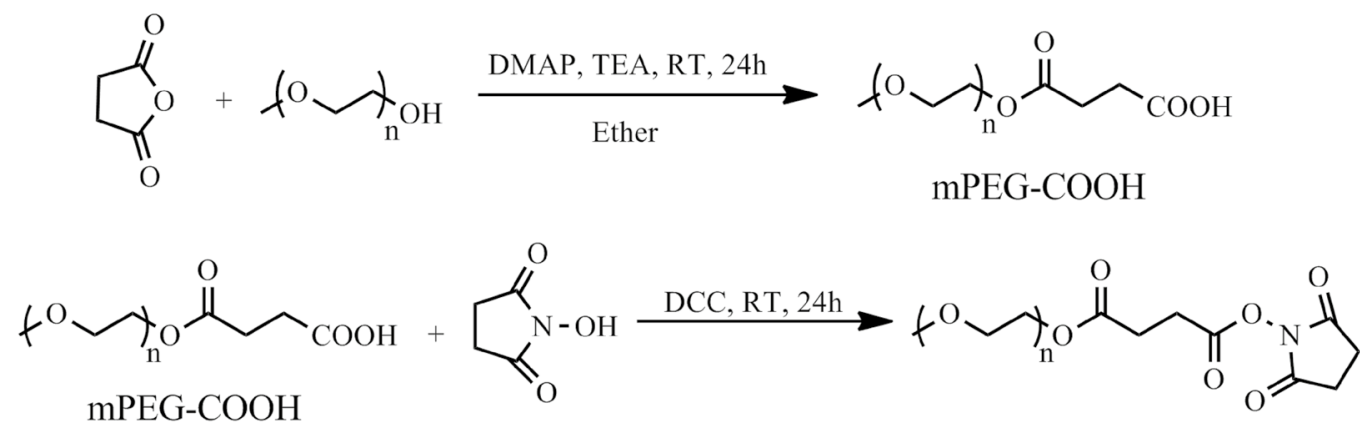

mPEG-NHS

$$
\begin{aligned}
\text { mPEG-NHS }+ \text { XGPLGIAGQr } 9 \text { X } \frac{\text { DMAP, EDC }}{\mathrm{N}_{2}} \longrightarrow \text { mPEG-Peptide } \\
\text { mPEG-Peptide }+ \text { PCL-NH } 2 \frac{\mathrm{DMAP}_{2} \text { DCC }}{\mathrm{DCM}, \mathrm{N}_{2}} \text { mPEG-Peptide-PCL }
\end{aligned}
$$

Fig. 1 Reaction scheme for elastomer preparation

mPEG-COOH (5.0 g, $2.5 \mathrm{mmol})$ and N-hydroxy succinimide $(1.2 \mathrm{~g}, 10 \mathrm{mmol})$ were dissolved in acetonitrile $(60 \mathrm{~mL})$, followed by addition of $N, N^{\prime}$ dicyclohexylcarbodiimide (DCC, $1.0316 \mathrm{~g}, 5 \mathrm{mmol}$ ). The reaction was carried out under $\mathrm{N}_{2}$ protection at room temperature for $24 \mathrm{~h}$. The purification process used was the same as that used for mPEG-COOH.

\section{Synthesis of mPEG-Peptide-PCL}

The peptide (50 mg, $0.0213 \mathrm{mmol})$, 1-ethyl-3-(3dimethylaminopropyl)-carbodiimide hydrochloride (EDC, $27.3 \mathrm{mg}, 0.142 \mathrm{mmol}$ ), and DMAP (17.4 mg, $0.142 \mathrm{mmol}$ ) were dissolved in acetonitrile-water solution $(20 / 80,10 \mathrm{~mL})$, and the mixture was stirred under dry nitrogen at $0{ }^{\circ} \mathrm{C}$ for $2 \mathrm{~h}$ to activate the peptide. Thereafter, mPEG-NHS ( $49.9 \mathrm{mg}, 0.0178 \mathrm{mmol}$ ) was mixed into the reaction solution, and transesterification was allowed to occur at room temperature for $24 \mathrm{~h}$. The mPEG-Peptide solution was purified by dialysis (Mw: 3500) for $72 \mathrm{~h}$, and lyophilized to the powder form. The $\mathrm{Mn}, \mathrm{Mw}$, and PDI were measured by GPC [33].

mPEG-Peptide (100 mg, $0.0194 \mathrm{mmol}$ ), DCC (40 mg, $0.1942 \mathrm{mmol})$, and $N$-hydroxy succinimide $(23.7 \mathrm{mg}$, $0.1942 \mathrm{mmol})$ were dissolved in DCM $(10 \mathrm{~mL})$, followed by stirring of the mixture under dry nitrogen at $0{ }^{\circ} \mathrm{C}$ for 2 h. Later, PCL- $\mathrm{NH}_{2}$ (165 mg, $\left.0.0291 \mathrm{mmol}\right)$ was added 
to the mixture, and the mixture was further stirred at room temperature for $96 \mathrm{~h}$. After the reaction was completed, the mPEG-Peptide-PCL solution was purified by dialysis (Mw: 7000) for $72 \mathrm{~h}$, and lyophilized to powder. The structure of mPEG-Peptide-PCL was confirmed by Fourier transform infrared (FT-IR) spectroscopy (Nicolet 6700; Thermo Fisher Scientific, USA) and ${ }^{1} \mathrm{H}-\mathrm{NMR}$ spectroscopy, and the $\mathrm{Mn}, \mathrm{Mw}$, and PDI of mPEGPeptide-PCL were measured by GPC [33]. Meanwhile, mPEG-PCL as a contrast compound was aggregated by mPEG and $\varepsilon$-caprolactone as per the method described in "Synthesis of PCL- $\mathrm{NH}_{2}$ " section.

\section{Preparation of Cur-loaded NPs}

Cur-P-NPs were prepared by the emulsion-solvent evaporation method. The optimal conditions for the preparation were as follows: Cur $(2.4 \mathrm{mg})$ and $\mathrm{mPEG}-$ Peptide-PCL (24.0 mg) were co-dissolved in $2 \mathrm{~mL}$ acetone, and added drop-wise to $10 \mathrm{~mL}$ of an aqueous phase containing Poloxamer-188 (20.0 mg) under magnetic stirring. The mixture was stirred for $4 \mathrm{~h}$ to remove acetone. The NP suspension was then filtrated through $0.45 \mu \mathrm{m}$ filter membrane to remove the unwrapped Cur and achieve a homogeneous suspension. At last, the nanoscaled suspensions were centrifuged at 19,000 rpm for $30 \mathrm{~min}$. The precipitate was collected and washed twice with deionized water, and lyophilized. The fundamental characterization of particle size, polymer dispersity index (PDI), and Zeta potential were measured by a laser particle analyzer (Malvern Zetasizer Nano-ZS90; Malvern, UK).

\section{Entrapment efficiency (EE) and drug loading (DL)}

The drug content of Cur-P-NPs was determined by ultraviolet spectrophotometry with a detection wavelength of $420 \mathrm{~nm}$. Drug entrapment efficiency (EE\%) and drugloading (DL\%) content were calculated based on a calibration curve. The equations used were as follows:

$$
\begin{aligned}
& \mathrm{EE} \%=\frac{\text { Weight of drug in nanoparticles }}{\text { Weight of feed drug }} \times 100 \\
& \mathrm{DL} \%=\frac{\text { Weight of drug in nanoparticles }}{\text { Weight of nanoparticles }} \times 100
\end{aligned}
$$

\section{Morphological analysis}

The morphology of the Cur-P-NPs was observed by transmission electron microscopy (TEM) on a JEOL JEM-1010 at 40,000 $\times$ magnification.

\section{X-ray diffraction (XRD)}

For the study of the surface properties of Cur-P-NPs, $\mathrm{X}$-ray diffraction (XRD) analysis was carried out with the following parameters: output voltage $=40 \mathrm{kV}$, output current $=40 \mathrm{~mA}$, and wave length $=0.1546 \mathrm{~nm}$.

\section{In vitro stability of mPEG-Peptide-PCL and Cur-P-NPs}

The mPEG-Peptide-PCL (100 mg) was dissolved in $10 \mathrm{~mL}$ tetrahydrofuran. Then, $2 \mathrm{~mL}$ of the mPEG-Peptide-PCL solution was diluted four-fold using 0.1 M PBS ( $\mathrm{pH} 7.4$ ), DMEM, and fetal bovine serum and incubated at $37^{\circ} \mathrm{C}$. At every given time point $(0,1,4,8$, and $24 \mathrm{~h}), 1 \mathrm{~mL}$ of the sample solution was collected (for fetal bovine serum sample, excess acetonitrile was added to remove the protein, followed by centrifugation), and the $\mathrm{Mn}, \mathrm{Mw}$, and PDI of mPEG-Peptide-PCL were measured using GPC as described above.

Cur-P-NPs solution $(2 \mathrm{~mL})$ was diluted four-fold using $0.1 \mathrm{M}$ PBS (pH 7.4), DMEM, and fetal bovine serum and incubated at $37{ }^{\circ} \mathrm{C}$. At every given time point $(0,1,4$, 8 and $24 \mathrm{~h}), 1 \mathrm{~mL}$ of the sample solution was collected (for fetal bovine serum sample, excess acetonitrile was added to remove the protein, followed by centrifugation), and the particle diameter and PDI of Cur-P-NPs were measured.

\section{In vitro drug release}

In vitro drug release was studied by dialysis. Cur-DMSO $(5 \mathrm{~mL})$ and Cur-P-NPs $(5 \mathrm{~mL} \times 2)$ with the same Cur content $(150 \mu \mathrm{g} / \mathrm{mL})$ were prepared. Dialysis of CurDMSO, the control group, was carried out at $\mathrm{pH}$ 7.4, and that of Cur-P-NPs $(5 \mathrm{~mL} \times 2)$, the treatment group, was carried out at 7.4 and 6.5 , simulating the conditions of systemic circulation and weakly acidic tumor environment,respectively. The solutions were poured into dialysis bags ( $\mathrm{Mw} 14 \mathrm{kDa}$ ). Then, the bags were submerged in $50 \mathrm{~mL}$ PBS at the respective $\mathrm{pH}$ values, and placed in an incubator at $37.0^{\circ} \mathrm{C} \pm 0.5^{\circ} \mathrm{C}$ with shaking at $100 \mathrm{rpm}$. At predetermined time points $(0,1,2,4,6,12$, $24,36,48,60,72$, and $96 \mathrm{~h}$ ), $3.0 \mathrm{~mL}$ of external solution was removed and replaced with an equivalent volume of fresh dissolution medium. The Cur content was determined by ultraviolet spectrophotometry.

\section{Cell culture}

L929 mouse embryonic fibroblasts and A549 lung carcinoma cells were maintained in DMEM with $10 \%(\mathrm{v} / \mathrm{v})$ fetal calf serum, penicillin $(100 \mu \mathrm{g} / \mathrm{mL})$, and streptomy$\operatorname{cin}(100 \mu \mathrm{g} / \mathrm{mL})$, and incubated in a humid atmosphere at $37^{\circ} \mathrm{C}$ with $5 \% \mathrm{CO}_{2}$. 


\section{In vitro cytotoxicity of NPs}

The cytotoxicity of NPs was evaluated by the 3-(4,5-dimethylthiazol-2-yl)-2,5-diphenyltetrazolium bromide (MTT) assay using L929 mouse embryonic fibroblasts. Cells were seeded in 96-well plates at a density of $1 \times 10^{5}$ cells/well. After $24 \mathrm{~h}$ of appropriate growth, various doses of sterilized blank NP or medium only (negative control) were added, and the cells were incubated for $48 \mathrm{~h}$. All samples were prepared in triplicate. A $20 \mu \mathrm{L}$ volume of MTT labeling reagent was added, and cells were cultured for $4 \mathrm{~h}$ at $37^{\circ} \mathrm{C}$. The absorbance was measured at $570 \mathrm{~nm}$, and cell viability (\%) was represented as the ratio of the absorbance of the test and negative control solutions.

\section{In vitro anticancer activity assay}

The efficacy of Cur-P-NPs solution against lung cancer cell viability was assessed in A549 cell lines by MTT analysis. Cells were seeded in 96-well plates at a density of $1 \times 10^{5}$ cells/well, and incubated with $100 \mu \mathrm{L}$ of the different dilutions of Cur-P-NPs or medium only (negative control) for $48 \mathrm{~h}$. A $20-\mu \mathrm{L}$ volume of MTT labeling reagent was added, and cells were co-cultured for $4 \mathrm{~h}$ at $37{ }^{\circ} \mathrm{C}$. All samples were prepared in triplicate. The cell viability (\%) was determined as per the method described in "In vitro cytotoxicity of NPs" section.

\section{Cellular uptake}

L929 (as non-target cells) and A549 cells (as target cells) were seeded in 96 -well plates $\left(10^{5}\right.$ cells/well), respectively. Thereafter, $100 \mu \mathrm{L}$ of Cur-DMSO, blank NPs, Cur-NPs (prepared using mPEG-PCL without peptide modification), Cur-P-NPs, or DMSO only (negative control) with Cur content of $50 \mu \mathrm{g} / \mathrm{mL}$ were co-cultured at $37{ }^{\circ} \mathrm{C}$ for $4 \mathrm{~h}$. The medium was then discarded, and the cells were washed with PBS thrice. Cellular uptake was evaluated by fluorescence microscopy at $200 \times$ magnification (Eclipse Ti-S; Nikon, Tokyo, Japan).

\section{Endocytic mechanism of Cur-P-NPs}

To further study the endocytic mechanism of Cur-P-NPs in A549 cells, chlorpromazine (an endocytosis inhibitor of clathrin-mediated endocytosis), cytochalasin D (an endocytosis inhibitor of macropinocytosis mediated endocytosis), or genistein (an endocytosis inhibitor of caveolae-mediated endocytosis) were used, with no treatment as control [34]. Firstly, cells were seeded in 12 -well plates $\left(10^{5}\right.$ cells/well) and co-cultured at $37^{\circ} \mathrm{C}$ for $1 \mathrm{~h}$ with $100 \mu \mathrm{L}$ of the endocytosis inhibitors at concentrations of 1,5 , or $25 \mu \mathrm{M}$. The medium was removed and replaced with complete medium containing Cur-PNPs (Cur:50 $\mu \mathrm{g} / \mathrm{mL}$ ) and different inhibitors for another
15 min. Thereafter, the medium was removed and the cells were washed twice with PBS solution. The cells were finally analyzed by flow cytometry (Beckman Coulter Cytoflex; Beckman, USA). All experiments were carried out in triplicate.

\section{Biodistribution studies}

Pharmacokinetic distribution studies were performed in nude mice [35]. About $5 \times 10^{7}$ A549 cells in $200 \mu \mathrm{L}$ PBS were subcutaneously injected into the left hind flank of the mice. Once the tumors had reached $\sim 100 \mathrm{~mm}^{3}$ in size (typically 2 weeks later), $0.2 \mathrm{~mL}$ of Cur-DMSO, and Cur-NPs and Cur-P-NPs with a Cur content of $50 \mu \mathrm{g} /$ $\mathrm{mL}$ were injected in the tumor-bearing mice via the tail vein at a Cur dose of $1.5 \mathrm{mg} / \mathrm{kg}$. For the imaging studies, mice were anesthetized at the prescribed time points (1 and $6 \mathrm{~h}$ ), and the images were shot using a small animal imager (IVIS, Lumina XRMS III) with Ex $=488 \mathrm{~nm}$ and $\mathrm{Em}=520 \mathrm{~nm}$. All the samples were prepared in triplicate.

\section{Statistical analysis}

Results were expressed as mean \pm standard error of the mean. Differences between groups were examined for statistical significance with the Student's t-test, and P-values $<0.05$ were considered statistically significant.

\section{Results and discussion}

\section{Tri-block polymer characterization}

The polymer of mPEG-Peptide-PCL was characterized using FT-IR and ${ }^{1} \mathrm{H}-\mathrm{NMR}$ analyses. The FT-IR spectrum of mPEG-Peptide-PCL is presented in Fig. 2. Compared with that of mPEG-PCL, mPEG-Peptide and PCL- $\mathrm{NH}_{2}$ (Additional file 1: Figures S1-S3), the peak at $3436.7 \mathrm{~cm}^{-1}$ corresponds to the $\mathrm{N}-\mathrm{H}$ bond stretching in the peptide linkage, while the peaks at 1628.9 and $1538.5 \mathrm{~cm}^{-1}$, which are attributed to the twisting vibrations of $\mathrm{N}-\mathrm{H}$ bond, were observed very clearly. The bands at 2925.8 and $2866.7 \mathrm{~cm}^{-1}$ reflect the $\mathrm{C}-\mathrm{H}$ stretching vibrations of the methylene group in PCL and $\mathrm{MPEG}$, respectively. Additionally, the signals at 1725.0 and $1243.6 \mathrm{~cm}^{-1}$ (or $1189.5 \mathrm{~cm}^{-1}$ ) represent formation of the $\mathrm{C}=\mathrm{O}$ and $\mathrm{C}-\mathrm{O}-\mathrm{C}$ bonds in the ester linkage. The corresponding ${ }^{1} \mathrm{H}-\mathrm{NMR}$ spectra and peak assignments are shown in Fig. 3a, b. The characteristic peaks of the peptide are showed at $1.72,1.25$ and $0.88 \mathrm{ppm}$, respectively (Fig. 3a). Compared to the peptide, the peak at $3.66 \mathrm{ppm}$ is ascribed to the protons of the methylene group in mPEG, while the peaks at 4.08, 2.32, 1.67, and $1.40 \mathrm{ppm}$ represent the methylene protons of PCL segments (Fig. 3b). All the above signals demonstrate the successful synthesis of the mPEG-Peptide-PCL. 


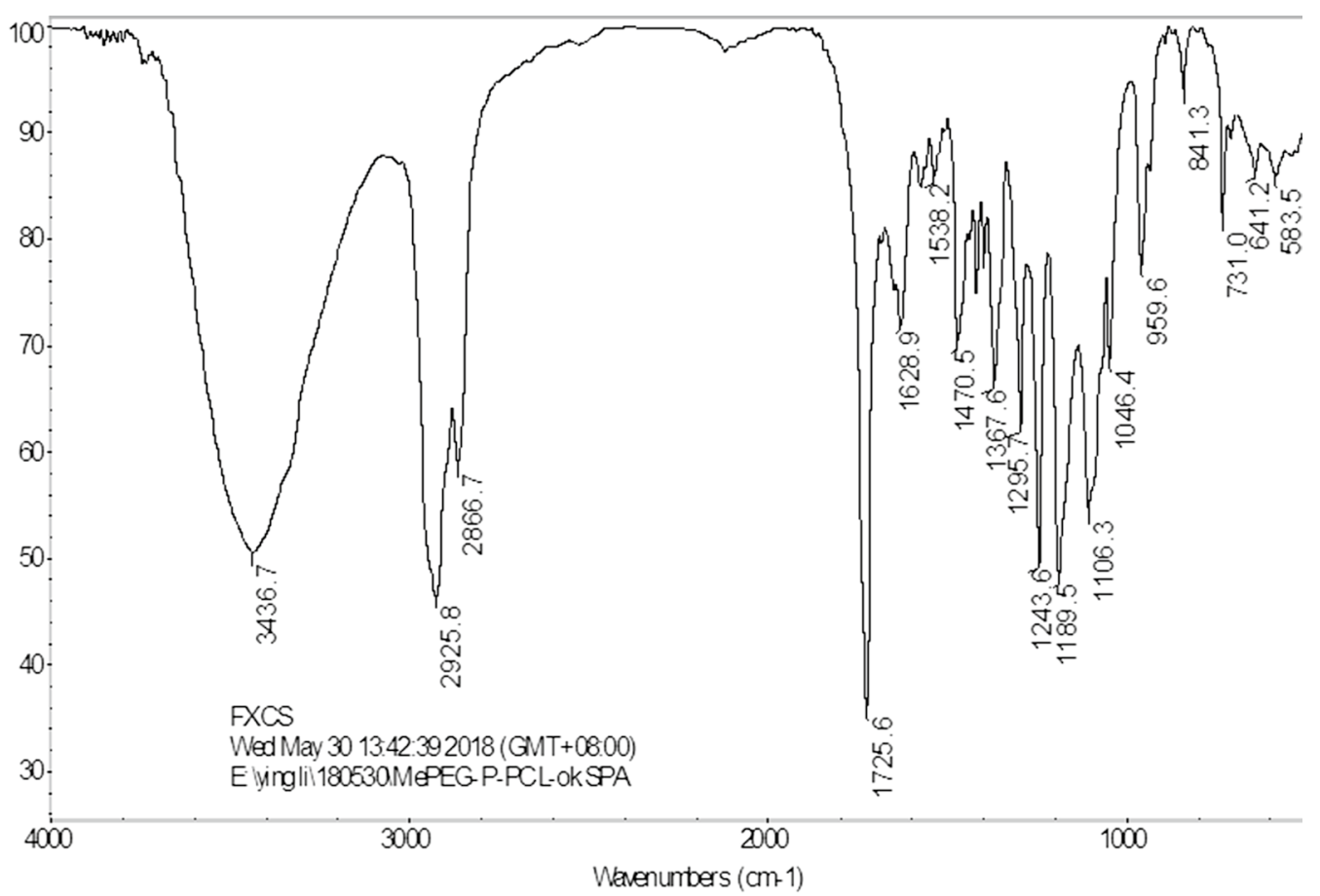

Fig. 2 FT-IR spectra of mPEG-Peptide-PCL
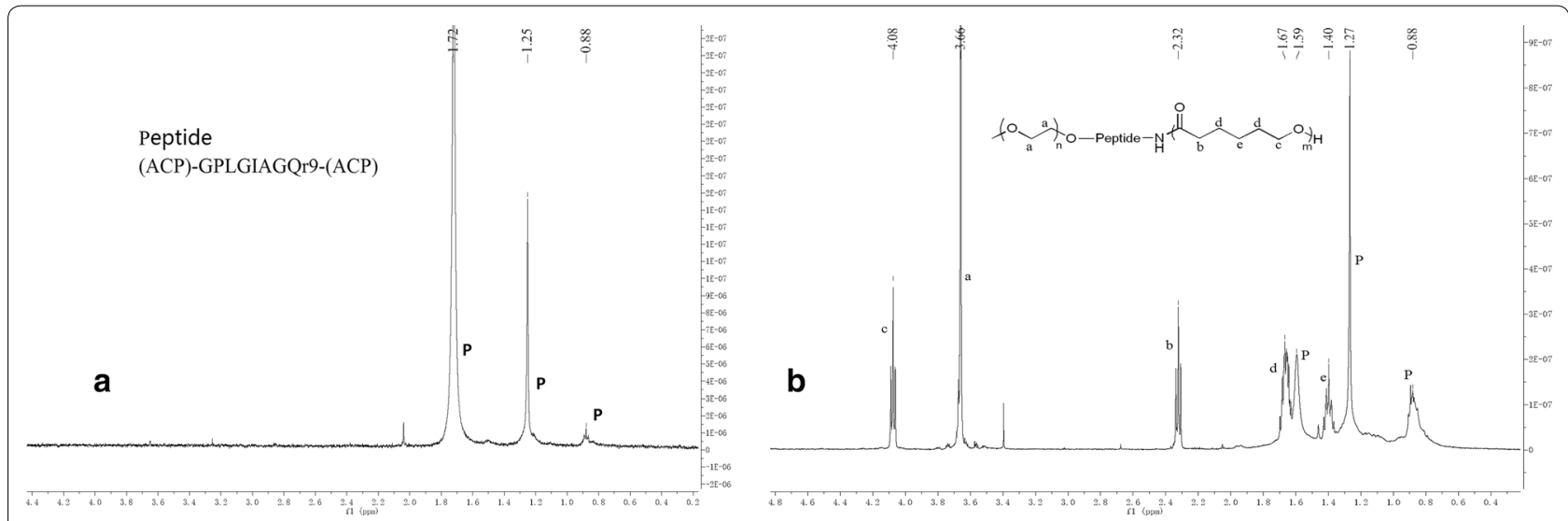

Fig. $3{ }^{1} \mathrm{H}-\mathrm{NMR}$ spectra of peptide (a) and mPEG-Peptide-PCL (b)

Table $1 \mathrm{Mn}$, Mw, and PDI of the prepolymers

\begin{tabular}{lcrc}
\hline & Mn & Mw & PDI \\
\hline PCL-NH 2 & 4716 & 5666 & 1.20 \\
mPEG-Peptide & 6065 & 6259 & 1.03 \\
mPEG-Peptide-PCL & 9684 & 12,614 & 1.30 \\
\hline
\end{tabular}

Besides, the Mn, Mw, and PDI of the prepolymers measured by GPC were listed in Table 1 . The molecular weight of $\mathrm{mPEG}$-Peptide-PCL almost equaled the sum of those of PCL- $\mathrm{NH}_{2}$ and mPEG-Peptide, which indicated the regulation of synthesis. Meanwhile, mPEGPeptide-PCL with the narrow PDI value was beneficial to the stability of the nanoparticles preparation. 
Table 2 Physicochemical characteristics of Cur-P-NPs

\begin{tabular}{|c|c|c|c|c|c|}
\hline Sample & Particle size (nm) & PDI & Zeta potentials (mV) & EE\% & DL\% \\
\hline Cur-P-NPs & $159.7 \pm 2.566$ & $0.116 \pm 0.017$ & $5.74 \pm 1.46$ & 80.12 & 7.58 \\
\hline Blank P-NPs & $180.3 \pm 2.227$ & $0.131 \pm 0.025$ & $3.48 \pm 0.408$ & - & - \\
\hline
\end{tabular}

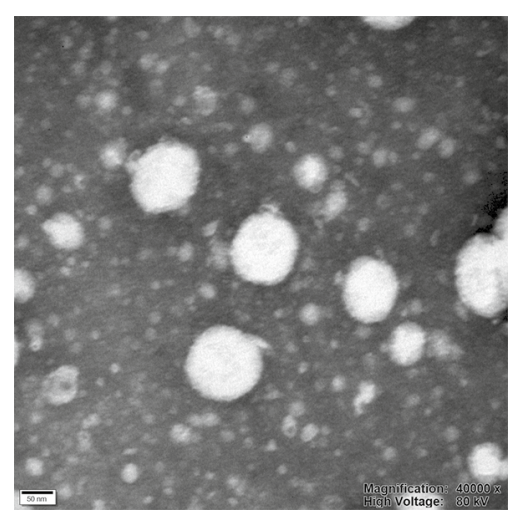

Fig. 4 TEM photograph of Cur-P-NPs (under $\times 40,000$ magnification)

\section{Characterization of NPs}

mPEG-Peptide-PCL polymer self-assembled to form biodegradation nanoparticles (Cur-P-NPs and blank P-NPs) with a hydrophilic shell (mPEG and peptide segment) and hydrophobic core (PCL segment). The particle sizes, zeta potentials, and EE and DL values are listed in Table 2. The average diameters of Cur-P-NPs and free P-NPs were 159.7 and $180.3 \mathrm{~nm}$ with PDI of 0.116 and 0.131 , respectively, indicating a relatively narrow size distribution for Cur-P-NPs and free P-NPs. The zeta potentials ranged from 3.48 to $5.74 \mathrm{mV}$. The positively charged corona could prevent nanoparticle aggregation due to electrostatic repulsion, improving the cellular uptake efficiency. Moreover, the EE\% and DL\% values of Cur-P-NPs were 80.12 and $7.58 \%$, respectively.

According to the results observed in the electron micrographs (Fig. 4), the Cur-P-NPs possess a nearspherical shape, and were uniformly distributed in the suspension.

XRD analysis (Fig. 5) revealed the surface characteristics of native Cur, free P-NPs, and Cur-P-NPs. There are sharp, characteristic peaks in native Cur. However, these peaks disappeared in Cur-P-NPs, indicating that Cur was trapped in the NPs.

\section{In vitro stability of mPEG-Peptide-PCL and Cur-P-NPs}

To preliminarily evaluate the validity of enzyme-responsive nanoparticles, the stability of mPEG-Peptide-PCL and Cur-P-NPs in PBS, DMEM, and fetal bovine serum

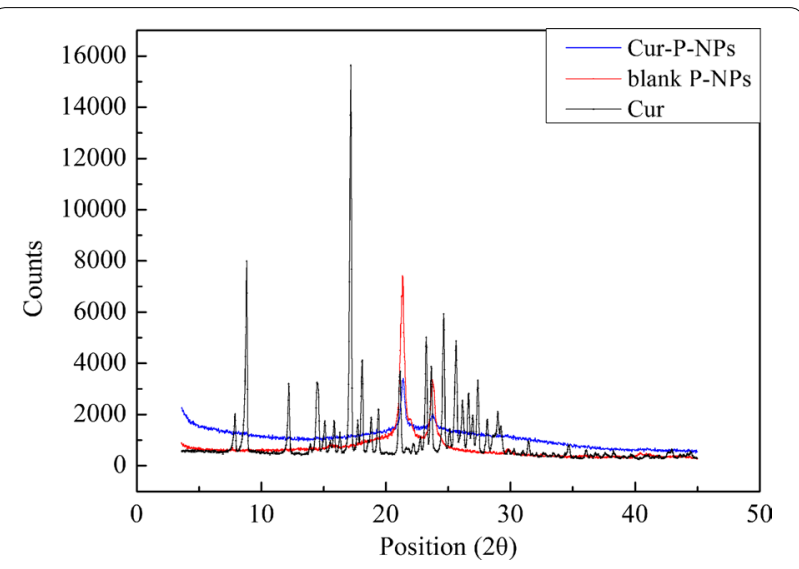

Fig. 5 X-ray diffraction curve of Cur, Blank-NPs, and Cur-P-NPs

were studied, respectively. mPEG-Peptide-PCL displayed excellent biostability in PBS and DMEM with Mn values changing to 300 and 700 Da, respectively (Fig. 6a, b). Both PDI were also stable at about 1.30. Moreover, the Mn of mPEG-Peptide-PCL increased to a minor extent to about $1000 \mathrm{Da}$ (Fig. 6c) after incubation in fetal bovine serum, suggesting that some short chain polypeptide was adsorbed on the materials. For all the solutions, the Mn value of mPEG-Peptide-PCL did not show an obvious decrease [more than 1900; mPEG $(\mathrm{Mn}=1900)$ ], indicating that the hydrolysis of the peptide in mPEG-PeptidePCL did not occur.

In addition, Cur-P-NPs displayed prominent stability in PBS and DMEM for $24 \mathrm{~h}$ with particle sizes of 170 and $175 \mathrm{~nm}$, respectively (Fig. 7a, b). On the other hand, the protein adsorption effect was also observed in fetal bovine serum (Fig. 7c). The size of Cur-P-NPs increased in the first $8 \mathrm{~h}$. Thereafter, a particle size of $335 \mathrm{~nm}$ was maintained. In particular, $8 \mathrm{~h}$ after incubation, the size of Cur-P-NPs was constant, suggesting that Cur-P-NPs could be generally stable in the body.

\section{In vitro drug release}

Figure 8 shows the results of release kinetics of Cur from Cur-DMSO and Cur-P-NPs. On comparison of the release curves of Cur-DMSO and Cur-P-NPs at pH 7.4, Cur-P-NPs were found to show a lower release rate of Cur with $65.49 \%$ at $96 \mathrm{~h}$ than that of Cur-DMSO showing complete release at $36 \mathrm{~h}$. Therefore, Cur exhibits a 

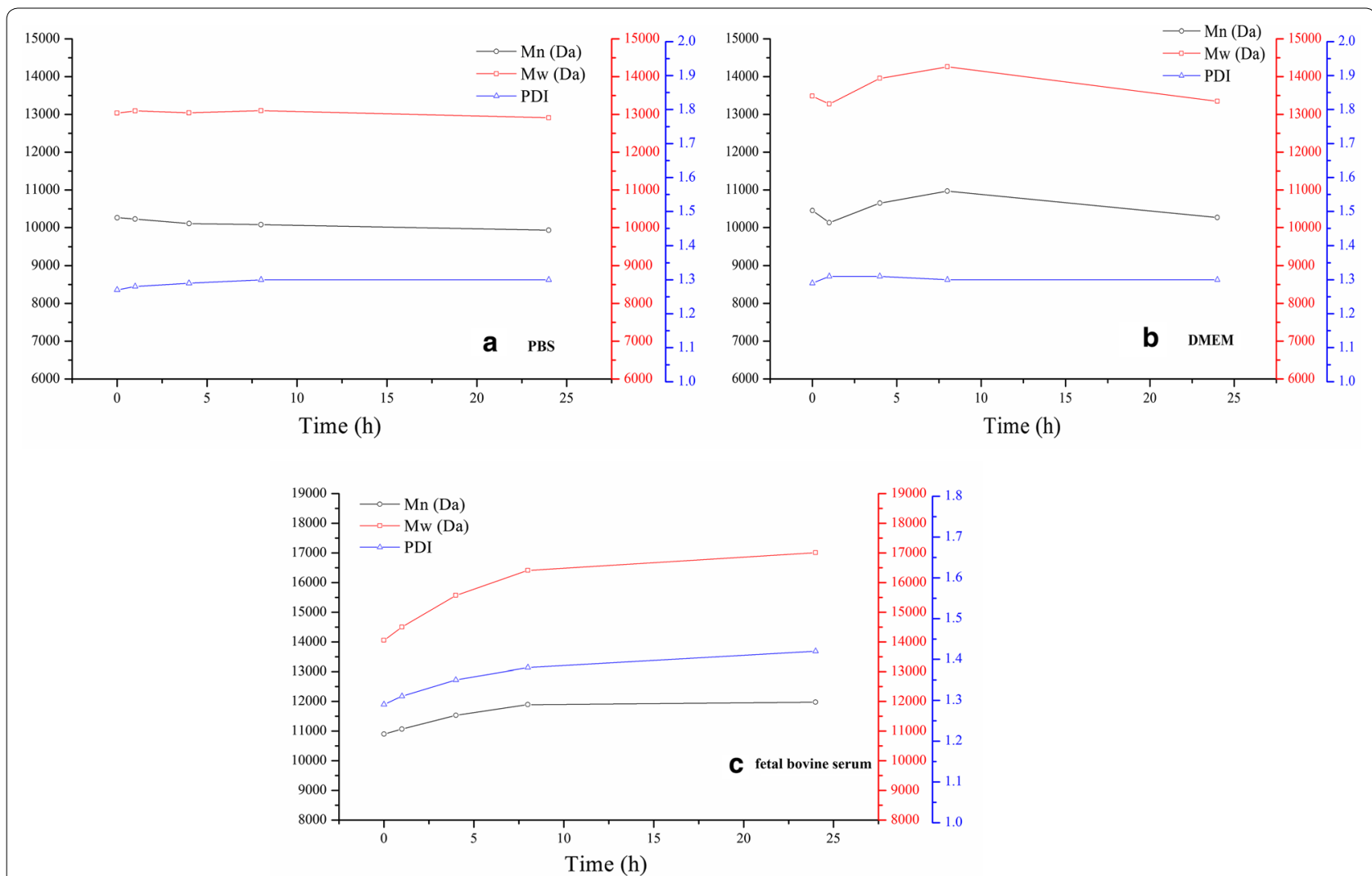

Fig. 6 In vitro stability of mPEG-Peptide-PCL a PBS, b DMEM, c fetal calf serum

sustained release profile from Cur-P-NPs. Moreover, the Cur-P-NP solution in PBS were assessed at $\mathrm{pH}$ values of 7.4 and 6.5 to simulate the conditions of systemic circulation and weakly acidic tumor environment, respectively. The release curves almost overlapped in the first $6 \mathrm{~h}$, thereafter, the final cumulative release rate of Cur reached $72.85 \%$ at $\mathrm{pH} 6.5$, only exceeding the rate at $\mathrm{pH}$ 7.4 to a small extent. Similar in vitro release profiles of Cur from the NPs would guarantee a stable intracellular concentration of Cur, leading to a consistent therapeutic effect.

\section{Cytotoxicity analysis}

The cytotoxicity of a material is one of the most important indicators for evaluation of biocompatibility of the delivery system. In this work, the viability of cells treated with blank P-NPs at different concentration is listed in Table 3. Cell viability decreased as the P-NP concentration increased from 0.51 to $2.05 \mathrm{mg} / \mathrm{mL}$. In addition, on decreasing the P-NP concentration from 0.51 to $0.13 \mathrm{mg} / \mathrm{mL}$, the cell viability was about $97 \%$, and only a minor change in viability was observed. However, all cell viabilities were above $87.86 \%$, indicating that blank P-NPs have good biocompatibility.

\section{In vitro anticancer activity assay}

A study on the anticancer activity in vitro was performed by MTT analysis. The results could be a foundation for pharmacodynamics study in vivo, and have been summarized in Fig. 9. Cell viabilities of 97.46, 60.93, 37.87, and $20.15 \%$ were measured after $48 \mathrm{~h}$ of incubation with equivalent concentrations at $1,5,25$, and $50 \mu \mathrm{g} / \mathrm{mL}$, respectively. A dose-dependent anticancer activity was observed. However, any obviously anticancer activity was observed at low concentration $(1 \mu \mathrm{g} / \mathrm{mL})$, thus more than $5 \mu \mathrm{g} / \mathrm{mL}$ is the suggested concentration of Cur for efficient treatment of lung tumor.

\section{Cellular uptake}

The ability of cellular uptake and the enzyme-targeted availability for Cur-P-NPs were assessed by fluorescence microscopy (Fig. 10). There was no fluorescence associated with the negative control of DMSO or blank NPs (Fig. 10A, B). As shown in Fig. 10C-E, Cur-NPs and 

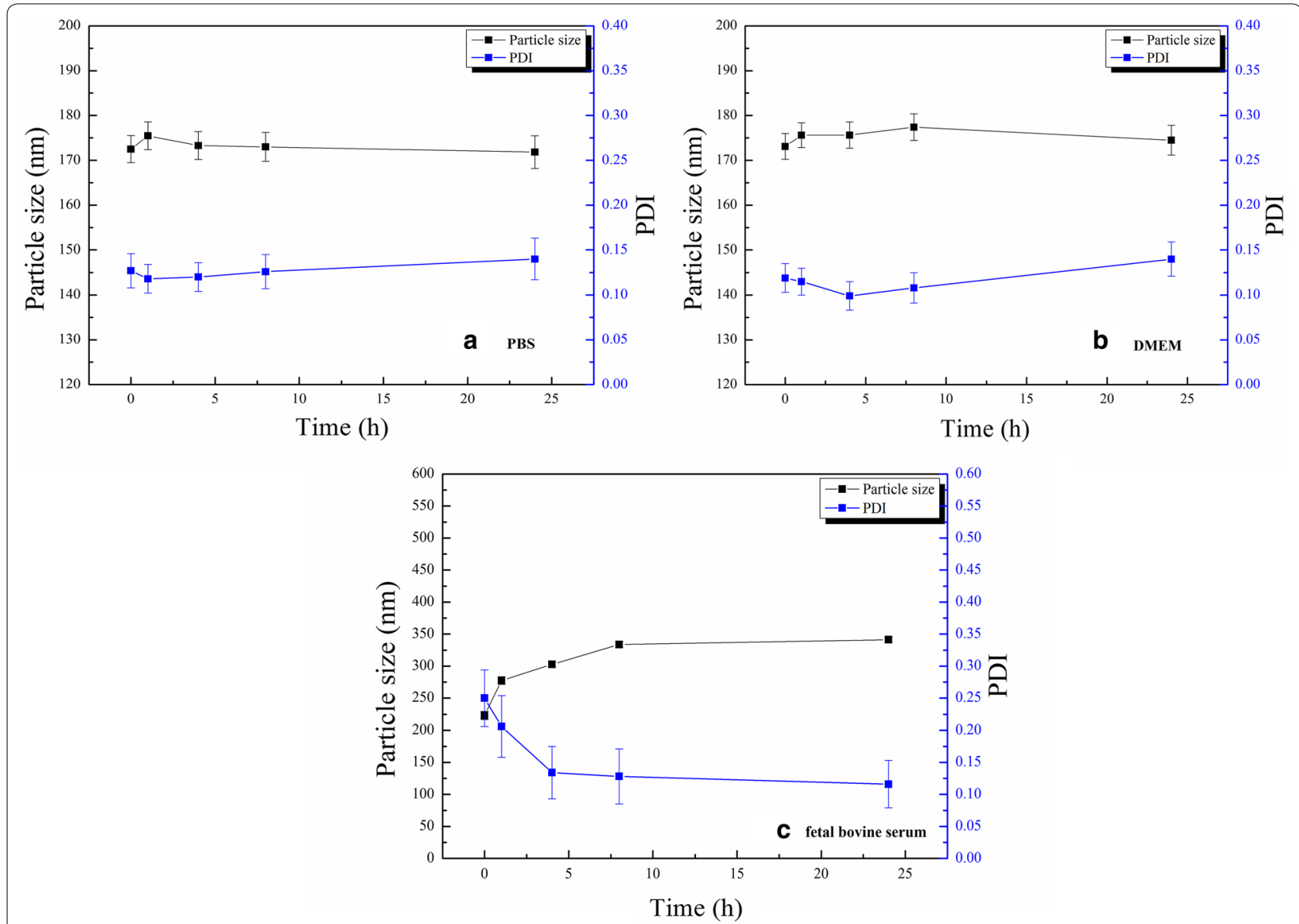

Fig. 7 In vitro stability of Cur-P-NPs a PBS, b DMEM, c fetal calf serum

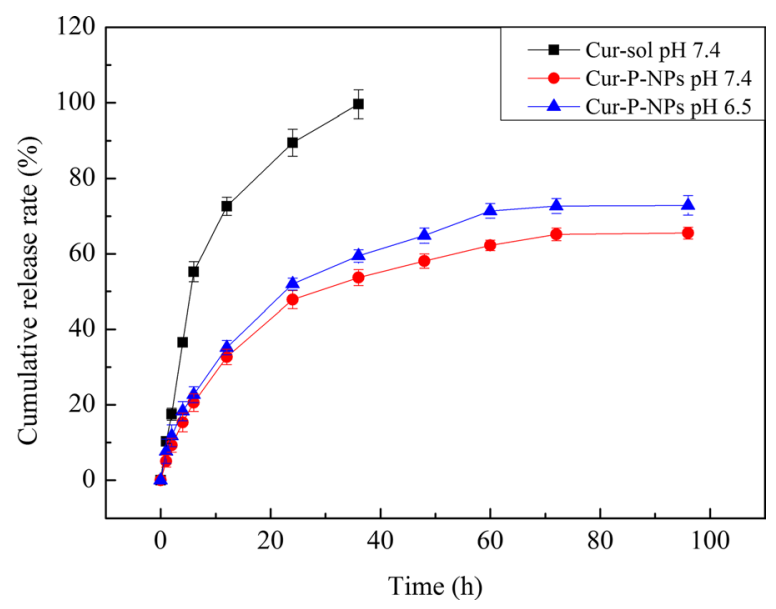

Fig. 8 Accumulative release of Cur in vitro

Cur-P-NPs showed a stronger fluorescence intensity than that of Cur-DMSO, demonstrating that the NPs had excellent permeability, which was consistent with the previous report [33]. On comparison with Fig. 10D, $\mathrm{E}$, it was observed that Cur-P-NPs had stronger fluorescence intensity than Cur-NPs, indicating a higher cellular uptake of Cur-P-NPs. It was reported that PEGylation could hinder the cellular uptake ability, but in the present study, Cur-P-NPs showed excellent uptake ability. A reasonable explanation is that the 'mPEG-GPLGIAGQ-r9' was cut off to 'mPEG-GPLGIAGQ' and 'r9-NPs' by the MMP enzyme in A549, leaving ' $r$ 9' together with NPs so that its uptake ability was tremendously improved.

To further evaluate the enzyme-targeted availability of Cur-P-NPs, the ability of cellular uptake was compared between L929 (non-target cells) and A549 (target cells) cells. As illustrated in Fig. 10E, F, more Cur-P-NPs were internalized by A549 than L929, demonstrating that the Cur-P-NPs are a site-specific drug delivery system targeting tumors.

\section{Endocytic mechanism of Cur-P-NPs}

In this study, chlorpromazine (an endocytosis inhibitor of clathrin-mediated endocytosis), cytochalasin D 
Table 3 Cytotoxicity evaluation of blank P-NPs for different concentration

\begin{tabular}{ll}
\hline Concentration $(\mathbf{m g} / \mathbf{m L})$ & Cell viability $(\%)$ \\
\hline 2.05 (origin solution) & $87.86 \pm 1.232$ \\
1.51 & $89.72 \pm 1.077$ \\
1.02 & $93.46 \pm 0.839$ \\
0.51 & $97.22 \pm 0.955$ \\
0.25 & $97.96 \pm 0.826$ \\
0.13 & $97.73 \pm 0.426$ \\
\hline
\end{tabular}

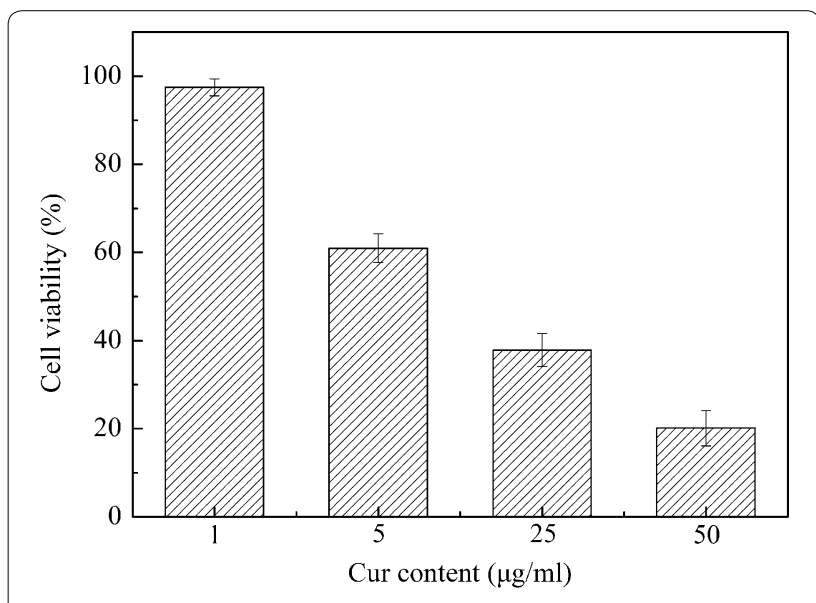

Fig. 9 Pharmacodynamics of Cur-P-NPs at different concentrations

(an endocytosis inhibitor of macropinocytosis mediated endocytosis), or genistein (an endocytosis inhibitor of caveolae-mediated endocytosis), as representative inhibitors with different inhibition mechanisms, were used to confirm the specific pathway for intracellular transport of mPEG-P-NPs. Results (Fig. 11) showed that cytochalasin D (macropinocytosis inhibitor) displayed the strongest inhibition with the uptake efficiency increasing from 51.31 to $69.54 \%$, and the uptake efficiency was affected in a dose-dependent manner. Chlorpromazine and genistein (clathrin-mediated endocytosis and caveolaemediated endocytosis) showed no significant inhibition at an uptake efficiency higher than $86.49 \%$. These results highlighted that macropinocytosis was the main uptake mechanism for successful internalization of Cur-P-NPs into A549 cells.

\section{Biodistribution studies}

To further test the targeting effect of Cur-P-NPs, CurDMSO and Cur-NPs (without peptide modification, prepared using mPEG-PCL) were used as the control groups. Real-time fluorescence images for in vivo Cur distribution are shown in Fig. 12. For Cur-DMSO, Cur was measured at very low levels in the tumor at $1 \mathrm{~h}$; however, $6 \mathrm{~h}$ later, low fluorescence was observed in the tumor. Most of the Cur was found to accumulate in the abdomen, and the fluorescence effect became weak with time. Poor bioavailability and targeting by the Cur-DMSO resulted in simple passive diffusion and no drug release as well as rapid metabolism of Cur. For Cur-P-NPs and Cur-NPs, Cur-loaded nanoparticles enter cells mainly via active transport, and both nanoparticle preparations possess the property of sustained release. Therefore, a weaker fluorescence intensity was measured in the whole body compared to that of Cur-DMSO. With continuous release of Cur in vivo, brighter fluorescence is visible in the live animal and more Cur accumulation in the tumor (better tumor-targeting) was observed from 1 to $6 \mathrm{~h}$ after tail vein injection. Especially for Cur-P-NPs, brighter fluorescence is visible in the tumor after injection in $1 \mathrm{~h}$, demonstrating that besides the EPR effect (passive targeting), the peptide of GPLGIAGQr9 carry out active targeting efficiently and enhance cellular uptake.

\section{Conclusions}

In the current study, a novel mPEG-Peptide-PCL with enzyme sensitivity was successfully synthesized; the peptide can self-assemble to form nanoparticles as a biomimetic platform with tumor targeting ability. The cytotoxicity and stability analysis revealed that Cur-PNPs exhibited excellent biocompatibility and biostability. The in vitro release profiles of Cur from the NPs were observed to be similar to those observed under systemic circulation and a weakly acidic tumor environment, indicating a stable intracellular concentration of Cur and a consistent therapeutic effect. The cellular uptake 


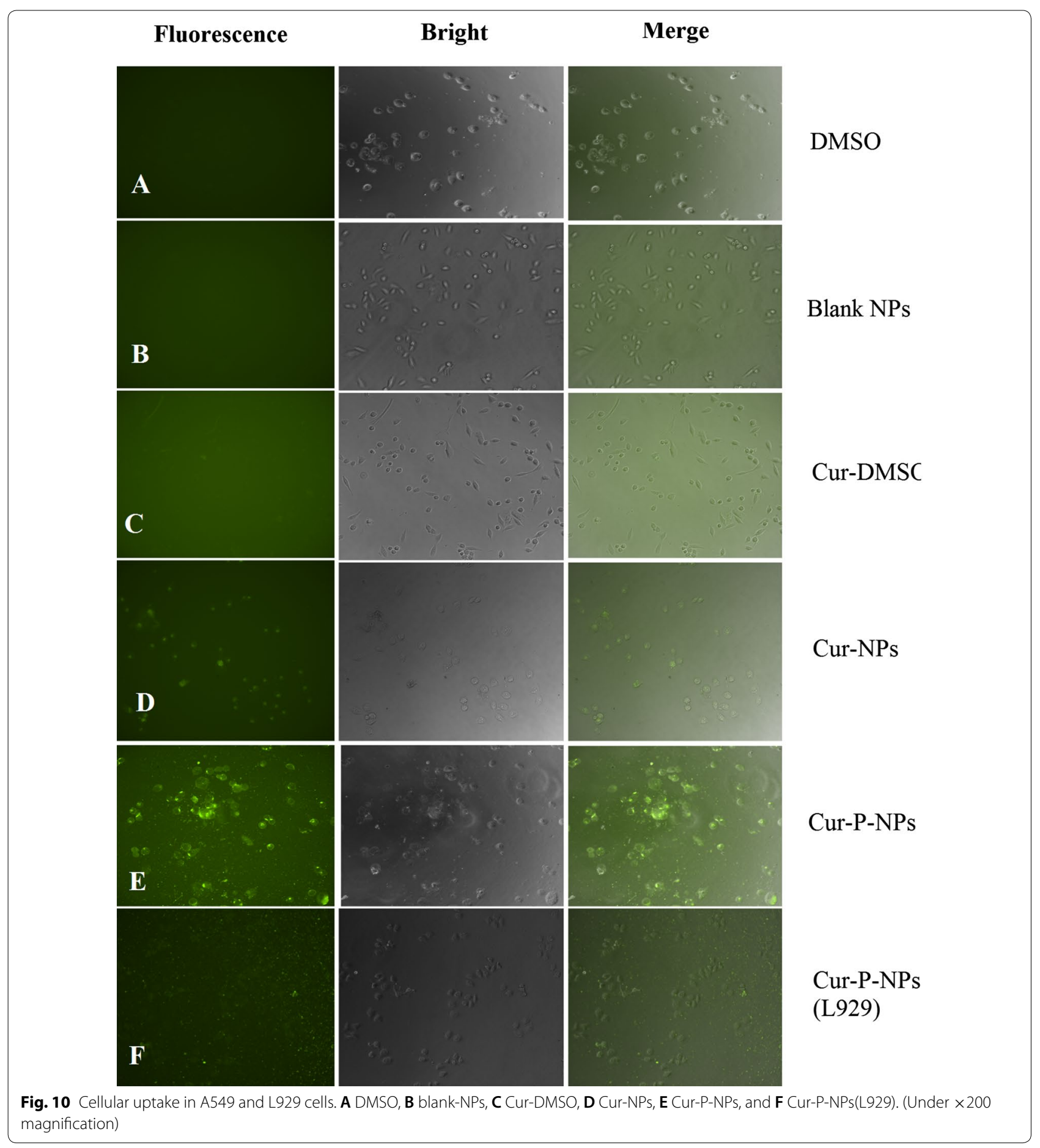

of drugs in tumor cells occurred mainly via macropinocytosis. Moreover, in nude mice, Cur-P-NPs displayed stronger fluorescence than Cur-DMSO and Cur-NPs, demonstrating more effective target efficiency and therapeutic effect. This result is in agreement with those reported by pharmacodynamics and cellular uptake 


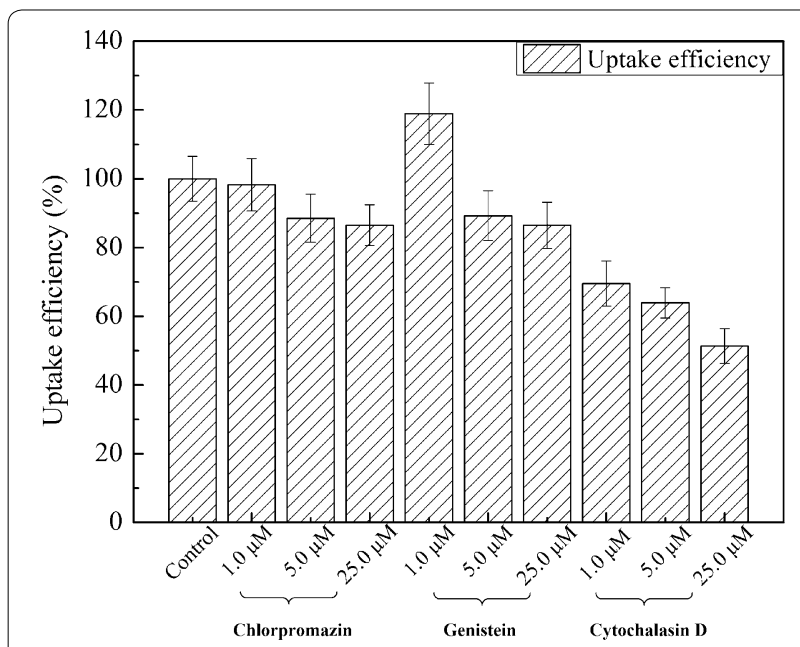

Fig. 11 Endocytic mechanism of Cur-P-NPs

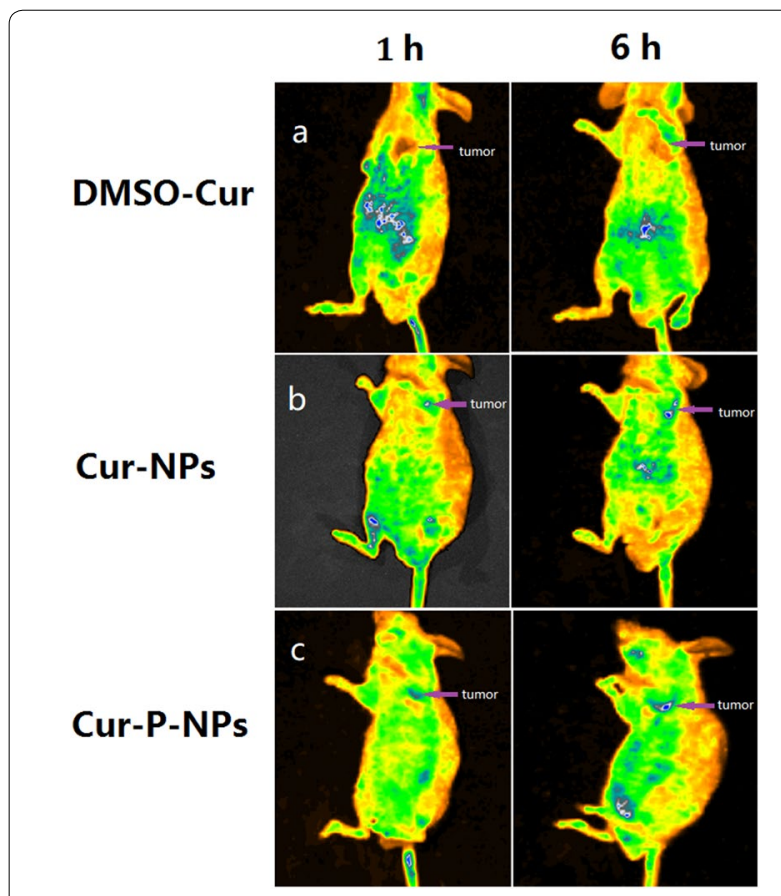

Fig. 12 Biodistribution of Cur in vivo after i.v. injection a Cur-DMSO, b Cur-NPs, c Cur-P-NPs

studies in vitro. Therefore, Cur-P-NPs can be employed as an active targeting drug delivery system for lung cancer treatment.

\section{Additional file}

Additional file 1: Figure S1. The FT-IR of MPEG-PCL. Figure S2. The FT-IR of mPEG-peptide. Figure $\mathbf{S 3}$. The FT-IR of PCL-NH ${ }_{2}$.

\section{Abbreviations}

(ACP)-GPLGIAGQrrrrrrrrr-(ACP):

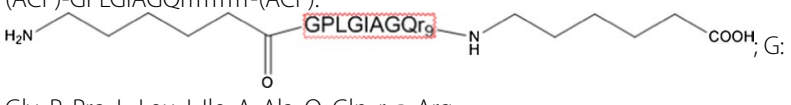

Gly; P: Pro; L: Leu; I: lle; A: Ala; Q: Gln; r: D-Arg.

\section{Authors' contributions}

FyG and GsY conceived and designed the experiments. FyG, JqW, WcW, and DxH performed the experiments. FyG, QyY, and QIY analyzed the data. FyG, YG, and GsY drafted and wrote the manuscript. All authors read and approved the final manuscript.

\section{Competing interests}

The authors declare that they have no competing interests.

\section{Consent for publication}

All authors have provided consent for the manuscript to be published.

\section{Ethics approval and consent to participate}

All animal experiments were performed in compliance with the local ethics committee of the ZJUT.

\section{Funding}

This work was financial supported by the National Natural Science Foundation of China (No. 21376223).

\section{Publisher's Note}

Springer Nature remains neutral with regard to jurisdictional claims in published maps and institutional affiliations.

Received: 13 March 2018 Accepted: 6 July 2018

Published online: 16 July 2018

\section{References}

1. Shi CS, Yu HY, Sun DJ, Ma LL, Tang ZH, Xiao QS, Chen XS. Cisplatin-loaded polymeric nanoparticles: characterization and potential exploitation for the treatment of non-small cell lung carcinoma. Acta Biomater. 2015;18:68-76.

2. Su YJ, Hu YH, Wang Y, Xu XT, Yuan Y, Li YM, Wang ZY, Chen KR, Zhang FR, Ding XF, et al. A precision-guided MWNT mediated reawakening the sunk synergy in RAS for anti-angiogenesis lung cancer therapy. Biomaterials. 2017;139:75-90.

3. Carozzi FM, Bisanzi S, Carrozzi L, Falaschi F, Pegna AL, Mascalchi M, Picozzi G, Peluso M, Sani C, Greco L, et al. Multimodal lung cancer screening using the ITALUNG biomarker panel and low dose computed tomography. Results of the ITALUNG biomarker study. Int I Cancer. 2017;141:94-101.

4. Torre LA, Bray F, Siegel RL, Ferlay J, Lortet-Tieulent J, Jemal A. Global cancer statistics, 2012. Ca-a Cancer J Clin. 2015;65:87-108.

5. Siegel RL, Miller KD, Jemal A. Cancer statistics, 2016. Ca-a Cancer J Clin. 2016;66:7-30

6. Mandal B, Mittal NK, Balabathula P, Thoma LA, Wood GC. Development and in vitro evaluation of core-shell type lipid-polymer hybrid nanoparticles for the delivery of erlotinib in non-small cell lung cancer. Eur J Pharm Sci. 2016;81:162-71.

7. Alibolandi M, Ramezani M, Abnous K, Sadeghi F, Atyabi F, Asouri M, Ahmadi AA, Hadizadeh F. In vitro and in vivo evaluation of therapy targeting epithelial-cell adhesion-molecule aptamers for non-small cell lung cancer. J Control Release. 2015;209:88-100.

8. Bremnes RM, Camps C, Sirera R. Angiogenesis in non-small cell lung cancer: the prognostic impact of neoangiogenesis and the cytokines VEGF and bFGF in tumours and blood. Lung Cancer. 2006;51:143-58.

9. Farhat FS, Tfayli A, Fakhruddin N, Mahfouz R, Otrock ZK, Alameddine RS, Awada AH, Shamseddine A. Expression, prognostic and predictive impact of VEGF and bFGF in non-small cell lung cancer. Crit Rev Oncol Hematol. 2012;84:149-60. 
10. Goel A, Kunnumakkara AB, Aggarwal BB. Curcumin as "Curecumin": from kitchen to clinic. Biochem Pharmacol. 2008;75:787-809.

11. Maheshwari RK, Singh AK, Gaddipati J, Srimal RC. Multiple biological activities of curcumin: a short review. Life Sci. 2006;78:2081-7.

12. Bengmark S. Curcumin, an atoxic antioxidant and natural NFkappaB, cyclooxygenase-2, lipoxygenase, and inducible nitric oxide synthase inhibitor: a shield against acute and chronic diseases. JPEN J Parenter Enteral Nutr. 2006;30:45-51.

13. Jagetia GC, Rajanikant GK. Curcumin treatment enhances the repair and regeneration of wounds in mice exposed to hemibody gamma-irradiation. Plast Reconstr Surg. 2005;115:515-28.

14. Gopinath D, Ahmed MR, Gomathi K, Chitra K, Sehgal PK, Jayakumar R. Dermal wound healing processes with curcumin incorporated collagen films. Biomaterials. 2004;25:1911-7.

15. Gupta SC, Patchva S, Aggarwal BB. Therapeutic roles of curcumin: lessons learned from clinical trials. AAPS J. 2013;15:195-218.

16. Pandey N, Dhiman S, Srivastava T, Majumder S. Transition metal oxide nanoparticles are effective in inhibiting lung cancer cell survival in the hypoxic tumor microenvironment. Chem Biol Interact. 2016;254:221-30.

17. Madni A, Batool A, Noreen S, Maqbool I, Rehman F, Kashif PM, Tahir N, Raza A. Novel nanoparticulate systems for lung cancer therapy: an updated review. J Drug Target. 2017;25:499-512.

18. Sundarraj S, Thangam R, Sujitha MV, Vimala K, Kannan S. Ligand-conjugated mesoporous silica nanorattles based on enzyme targeted prodrug delivery system for effective lung cancer therapy. Toxicol Appl Pharmacol. 2014;275:232-43.

19. Peer D, Karp JM, Hong S, FaroKHzad OC, Margalit R, Langer R. Nanocarriers as an emerging platform for cancer therapy. Nat Nanotechnol. 2007;2:751-60.

20. Arruebo M, Fernandez-Pacheco R, Ibarra MR, Santamaria J. Magnetic nanoparticles for drug delivery. Nano Today. 2007:2:22-32.

21. Kang T, Li FY, Baik S, Shao W, Ling DS, Hyeon T. Surface design of magnetic nanoparticles for stimuli-responsive cancer imaging and therapy. Biomaterials. 2017;136:98-114.

22. Huang KW, Chieh JJ, Yeh CK, Liao SH, Lee YY, Hsiao PY, Wei WC, Yang HC, Horng HE. Ultrasound-induced magnetic imaging of tumors targeted by biofunctional magnetic nanoparticles. ACS Nano. 2017;11:3030-7.

23. Yang XY, Cai XQ, Yu AH, Xi YW, Zhai GX. Redox-sensitive self-assembled nanoparticles based on alpha-tocopherol succinate-modified heparin for intracellular delivery of paclitaxel. J Colloid Interface Sci. 2017:496:311-26.
24. Wu MM, Cao ZY, Zhao YF, Zeng R, Tu M, Zhao JH. Novel self-assembled pH-responsive biomimetic nanocarriers for drug delivery. Mater Sci Eng C Mater Biol Appl. 2016;64:346-53.

25. Chen WL, Yang SD, Li F, Li JZ, Yuan ZQ, Zhu WJ, Liu Y, Zhou XF, Liu C, Zhang XN. Tumor microenvironment-responsive micelles for pinpointed intracellular release of doxorubicin and enhanced anti-cancer efficiency. Int J Pharm. 2016;511:728-40.

26. Dissanayake S, Denny WA, Gamage S, Sarojini V. Recent developments in anticancer drug delivery using cell penetrating and tumor targeting peptides. J Control Release. 2017;250:62-76.

27. Grunwald B, Vandooren J, Locatelli E, Fiten P, Opdenakker G, Proost P, Kruger A, Lellouche JP, Israel LL, Shenkman L, Franchini MC. Matrix metalloproteinase-9 (MMP-9) as an activator of nanosystems for targeted drug delivery in pancreatic cancer. J Control Release. 2016;239:39-48.

28. Seleci M, Seleci DA, Ciftci M, Demirkol DO, Stahl F, Timur S, Scheper T, Yagci Y. Nanostructured amphiphilic star-hyperbranched block copolymers for drug delivery. Langmuir. 2015;31:4542-51.

29. Zhu L, Wang T, Perche F, Taigind A, Torchilin VP. Enhanced anticancer activity of nanopreparation containing an MMP2-sensitive PEG-drug conjugate and cell-penetrating moiety. Proc Natl Acad Sci USA. 2013;110:17047-52

30. Lin YA, Ou YC, Cheetham AG, Cui H. Rational design of MMP degradable peptide-based supramolecular filaments. Biomacromol. 2014;15:1419-27.

31. Kratz F, Drevs J, Bing G, Stockmar C, Scheuermann K, Lazar P, Unger C. Development and in vitro efficacy of novel MMP2 and MMP9 specific doxorubicin albumin conjugates. Bioorg Med Chem Lett. 2001;11:2001-6.

32. Wang $H X$, Yang $X Z$, Sun $C Y$, Mao CQ, Zhu YH, Wang J. Matrix metalloproteinase 2-responsive micelle for siRNA delivery. Biomaterials. 2014:35:7622-34.

33. Guo F, Guo D, Zhang W, Yan Q, Yang Y, Hong W, Yang G. Preparation of curcumin-loaded PCL-PEG-PCL triblock copolymeric nanoparticles by a microchannel technology. Eur J Pharm Sci. 2017;99:328-36.

34. Wei T, Chen C, Liu J, Liu C, Posocco P, Liu XX, Cheng Q, Huo SD, Liang ZC, Fermeglia $\mathrm{M}$, et al. Anticancer drug nanomicelles formed by self-assembling amphiphilic dendrimer to combat cancer drug resistance. Proc Natl Acad Sci USA. 2015;112:2978-83.

35. Zhu YQ, Wang XX, Zhang J, Meng FH, Deng C, Cheng R, Jan FJ, Zhong $Z Y$. Exogenous vitamin $C$ boosts the antitumor efficacy of paclitaxel containing reduction-sensitive shell-sheddable micelles in vivo. J Control Release. 2017:250:9-19.
Ready to submit your research? Choose BMC and benefit from:

- fast, convenient online submission

- thorough peer review by experienced researchers in your field

- rapid publication on acceptance

- support for research data, including large and complex data types

- gold Open Access which fosters wider collaboration and increased citations

- maximum visibility for your research: over $100 \mathrm{M}$ website views per year

At BMC, research is always in progress.

Learn more biomedcentral.com/submissions 